\title{
Hemodynamic responses during graded and constant-load plantar flexion exercise in middle-aged men and women with type 2 diabetes
}

\author{
Catherine Kiely, ${ }^{1 *}$ Eamonn O'Connor, ${ }^{1 *}$ Donal O'Shea, ${ }^{2}$ Simon Green, ${ }^{3}$ and Mikel Egaña ${ }^{1}$ \\ ${ }^{1}$ Department of Physiology, School of Medicine, Trinity College Dublin, Dublin, Ireland; ${ }^{2}$ Endocrinology, St Columcille's \\ and St Vincent's Hospitals, Dublin, Ireland; and ${ }^{3}$ School of Science and Health and School of Medicine, University of \\ Western Sydney, Sydney, Australia
}

Submitted 24 June 2014; accepted in final form 11 August 2014

Kiely C, O'Connor E, O'Shea D, Green S, Egaña M. Hemodynamic responses during graded and constant-load plantar flexion exercise in middle-aged men and women with type 2 diabetes. $J$ Appl Physiol 117: 755-764, 2014. First published August 14, 2014; doi:10.1152/japplphysiol.00555.2014.-We tested the hypotheses that type 2 diabetes (T2D) impairs the 1) leg hemodynamic responses to an incremental intermittent plantar-flexion exercise and 2) dynamic responses of leg vascular conductance (LVC) during low-intensity (30\% maximal voluntary contraction, MVC) and high-intensity (70\% MVC) constant-load plantar-flexion exercise in the supine posture. Forty-four middle-aged individuals with T2D (14 women), and 35 healthy nondiabetic (ND) individuals (18 women) were tested. Leg blood flow (LBF) was measured between each contraction using venous occlusion plethysmography. During the incremental test peak force $\left(\mathrm{F}_{\text {peak }}\right)$ relative to MVC was significantly reduced $(P<0.05)$ in men and women with T2D compared with their respective nondiabetic counterparts. Peak LBF and the slope of LBF relative to percentage $\mathrm{F}_{\text {peak }}$ were also reduced $(P<0.05)$ in women with T2D compared with healthy women (peak blood flow, $460.6 \pm 126.8$ vs. $628.3 \pm$ $347.7 \mathrm{ml} / \mathrm{min}$; slope, $3.78 \pm 1.74$ vs. $5.85 \pm 3.14 \mathrm{ml} \cdot \mathrm{min}^{-1}$. $\% \mathrm{~F}_{\text {peak }}{ }^{-1}$ ) and in men with $\mathrm{T} 2 \mathrm{D}$ compared with nondiabetic men (peak blood flow, $621.7 \pm 241.3$ vs. $721.2 \pm 359.7 \mathrm{ml} / \mathrm{min}$; slope, $5.75 \pm 2.66$ vs. $\left.6.33 \pm 3.63 \mathrm{ml} \cdot \mathrm{min}^{-1} . \% \mathrm{~F}_{\text {peak }}{ }^{-1}\right)$. During constantload contractions at $30 \%$ MVC T2D did not affect the dynamic responses of LVC (LBF/MAP). However, at 70\% MVC [completed by a subgroup of participants ( 20 with T2D, 6 women; 13 ND, 6 women)] the time constant of the second growth phase of LVC was longer and the amplitude of the first growth phase was lower $(P<$ 0.05 for both) in men and women with T2D. The results suggest that the T2D-induced impairments in performance of the leg muscles are related to reductions in blood flow in both men and women.

vascular conductance; blood flow; type 2 diabetes; muscle; exercise

EXERCISE INTOLERANCE IS A major complication of type 2 diabetes (T2D) that is associated with worsening of cardiovascular outcomes and increased risk of mortality (45). Although the etiology of exercise intolerance in T2D is still not well understood, peak oxygen uptake $\left(\dot{\mathrm{V}}_{2}\right)$ responses to a graded exercise are reduced in men and women with T2D compared with nondiabetic healthy peers $(16,19,25,34)$, and the rate of increase in $\dot{\mathrm{V}}_{2}\left(\dot{\mathrm{V}}_{2}\right.$ kinetics) is slowed in younger and middle-aged men and women with T2D $(1,3,19,25,34)$ but not in older men with this disease (47). In healthy individuals, $\dot{\mathrm{V}}_{2}$ kinetics during cycling exercise are limited by the muscle's oxidative capacity rather than $\mathrm{O}_{2}$ delivery per se (30); however, it is likely that in patients with $\mathrm{T} 2 \mathrm{D}, \mathrm{V}_{2}$ kinetics are

\footnotetext{
* C. Kiely and E. O'Connor contributed equally to this work.

Address for reprint requests and other correspondence: M. Egaña, Dept. of Physiology, Trinity College Dublin, Dublin 2, Ireland (e-mail: megana @ tcd.ie).
}

limited, at least in part, by reduced $\mathrm{O}_{2}$ delivery to the contracting muscle.

Support for reduced $\mathrm{O}_{2}$ delivery as the source of the impairment in $\dot{\mathrm{V}}_{2}$ control can be found in reports showing significantly slower heavy intensity vascular conductance kinetics in the contracting calf muscle in women with T2D (20), as well as slowed microvascular blood flow kinetics during moderate cycling in men and women with T2D (1). In addition, steadystate measurements of femoral artery blood flow during cycling (15) and knee extension exercise (16) are also reduced in men and women with T2D compared with healthy controls. However, in contrast, in the Goto-Kakizaki (GK) type 2 diabetic rat vascular control was shown to be unaltered $(5,27)$. In addition, during low- and high-intensity handgrip exercise, brachial artery as well as skeletal muscle capillary blood flows are unaltered in middle-aged men and women with T2D free from microvascular disease (49), and normal skeletal muscle capillary flow responses to electrically stimulated contractions in Zucker diabetic fatty rats have also been observed (46).

The discrepancies observed between studies reporting steady-state blood flow responses might be related to the exercise model used, muscles studied, and/or to the fact that the GK rat represents a nonhyperinsulinemic diabetic model, whereas human patients are typically hyperinsulinemic. Regardless of the mechanism, however, the hyperemic responses in T2D reported in these previous studies are limited to submaximal exercise, and to our knowledge, no studies have explored the maximal hyperemic response or the slope of the hyperemic response to graded exercise in T2D. In addition, no previous studies have investigated the kinetic responses of leg vasodilation during light exercise, and given that people with T2D perceive even light routine daily activities as more difficult than healthy peers perceive them (13), it is relevant to explore whether the dynamic response characteristics of leg vascular conductance (LVC) during light exercise are affected in T2D.

Furthermore, whether the hyperemic/vasodilatory responses to exercise in T2D are sex-specific is also unclear. In our laboratory we have recently observed that the magnitude of impairment in peak $\dot{\mathrm{V}}_{2}$ and $\dot{\mathrm{V}}_{2}$ kinetics during moderate cycling were similar between middle-aged men and women with T2D compared with their healthy counterparts (25). In contrast, others have shown that reductions in peak exercise capacity are more pronounced in women with T2D than men (35), and it appears that the risk of cardiovascular morbidity and mortality is greater in women than men with T2D $(11,14$, 17). Accordingly, the present study aimed to investigate leg blood flow (LBF) and LVC responses to a maximal incremental and to a constant-load plantar-flexion exercise in men and women with T2D. Specifically, we tested the hypotheses that 
both men and women with T2D would show similar reductions in peak responses as well as hyperemic and vasodilatory responses to graded and constant-load exercise.

\section{MATERIALS AND METHODS}

\section{Subjects}

Seventy-nine volunteers, 44 being treated for T2D and 35 healthy controls matched for age and body mass index took part in this study (Table 1). Nondiabetic subjects (17 men, 18 women) were recruited from the general population. Subjects with T2D (30 men, 14 women) were recruited from the Diabetes Day Care centers at St. Columcille's and St. Vincent's Hospitals, Dublin, following a chart review. Subjects with T2D were included if they were treated by diet $(n=14)$ or oral hypoglycemic agents (metformin monotherapy $n=22$; metformin and sulphonylurea $n=8$ ). The duration of diabetes for all subjects ranged between 1 and $11 \mathrm{yr}$ (Table 1). Grounds for exclusion included evidence of peripheral arterial disease $(0.9<$ ankle brachial index $<1.3)$, HbA1c levels $>75 \mathrm{mmol} / \mathrm{mol}$, uncontrolled hypertension $(>160 / 90 \mathrm{mmHg})$, kidney dysfunction (consistent urinary protein $>200 \mathrm{mg} / \mathrm{dl}$ ), or liver dysfunction (urinary creatinine levels $>2.2 \mathrm{mg} / \mathrm{dl}$ ). Further grounds for exclusion included insulin- or thiazolidinedione-based treatment, because insulin use suggests a more advanced level of diabetes, whereas thiazolidinediones have been shown to improve exercise tolerance (29). All subjects with T2D underwent a stress test immediately prior to participation in the study to ensure absence of clinical evidence of ischemic heart disease. Individuals who demonstrated at least $1 \mathrm{~mm}$ horizontal or downsloping ST segment responses were excluded from participation (44). Subjects with controlled hypertension were admitted to the study; however, those using beta-blockers were excluded (8). Antihypertensive medication included angiotensinconverting-enzyme inhibitor monotherapy (ACE-I, $n=4$ ), angiotensin II type 1 receptor antagonist monotherapy (AIIRA, $n=4$ ), and combination of ACE-I and AIIRA $(n=4)$. All subjects were determined to be sedentary $(<1 \mathrm{hr} / \mathrm{wk}$ of moderate intensity exercise per week) for the previous 6 mo. Physical activity level was assessed by the use of 5-day RT3 triaxial accelerometers (Stay-Healthy, Monrovia, CA) during all waking hours (36), whereas the peak exercise capacity (peak $\mathrm{V}_{2}$ ) was assessed through performance on an incremental graded cycling test (Table 1). All subjects provided written informed consent prior to participation, and the study was approved by the Faculty of Health Science Research Ethics Committee and conducted in accordance with the Declaration of Helsinki.

\section{Experimental Design}

All participants visited the cardiovascular performance laboratory at Trinity College Dublin on two or three separate occasions separated by at least $48 \mathrm{~h}$. Of the female subjects, six were premenopausal (1 with T2D and 5 nondiabetics), and their testing dates were scheduled to occur during the midfollicular phase of their menstrual cycle (days $5-12$ ). Before each visit subjects were asked to refrain from consuming caffeine and alcohol in the $24 \mathrm{~h}$ prior to testing, in addition to limiting exercise to activities of daily living.

On visit 1, participants were initially familiarized with the calf plantar-flexion exercise protocol and performed six maximal voluntary contraction (MVC) efforts in the supine position separated by 1 min from which the highest effort was taken as MVC. On visit 2, participants performed three intermittent plantar-flexion exercise bouts of $6 \mathrm{~min}$ at $30 \% \mathrm{MVC}$, each separated by a resting period of 10 min followed by an incremental calf plantar-flexion test to exhaustion. Participants began the incremental test with an intermittent force production of $100 \mathrm{~N}$ for $2 \mathrm{~min}$ and thereafter, the required force was increased every 2 min by either $200 \mathrm{~N}$ (men) or $150 \mathrm{~N}$ (women) because prior unpublished data within our laboratory indicated that these increments would result in similar times to failure between men and women. Exercise was continued until failure, which was defined as the inability to achieve the target force requirement on three successive contractions (6). The peak force achieved was defined as the highest force that a subject could sustain for a minimum period of 1 min. Participants rested $\sim 30 \mathrm{~min}$ and then performed a forearm reactive hyperemia protocol in the supine position. This common test was performed to explore whether vascular dysfunction in T2D was present in the upper limb. Baseline forearm blood flow (FBF) responses were measured six times separated by a 15 -s rest. Then, ischemia was induced by inflating a cuff around the upper right arm to suprasystolic pressures $(\sim 220 \mathrm{mmHg}$ ) for a 5 -min period. Following release of the arterial occlusion, FBF was assessed at 10-s intervals for the first $5 \mathrm{~min}$, and then at 1-min intervals for 5 additional min. On visit 3, a subgroup of participants (20 with T2D, 14 men/6 women; and 13 nondiabetics, 7 men/ 6 women) returned to the labo-

Table 1. Physical characteristics and activity levels

\begin{tabular}{|c|c|c|c|c|}
\hline & \multicolumn{2}{|c|}{ Women } & \multicolumn{2}{|c|}{ Men } \\
\hline \multicolumn{5}{|l|}{ Physical characteristics } \\
\hline Body mass, $\mathrm{kg}$ & $77.2 \pm 11.7$ & $80.3 \pm 12.5$ & $93.8 \pm 11 *$ & $91.1 \pm 11.0^{*}$ \\
\hline BMI, $\mathrm{kg} / \mathrm{m}^{-2}$ & $29.6 \pm 3.9$ & $31.9 \pm 4.9$ & $29.3 \pm 3$ & $30 \pm 3.4$ \\
\hline Fasting glucose, $\mathrm{mmol} / \mathrm{liter}$ & $4.7 \pm 0.6 \dagger$ & $8.4 \pm 2.3$ & $4.8 \pm 0.6 \dagger$ & $7.2 \pm 1.5$ \\
\hline $\mathrm{HbA}_{1 \mathrm{c}}, \mathrm{mmol} / \mathrm{mol}$ & $36.3 \pm 3.6 \dagger$ & $48.4 \pm 8.2$ & $36.7 \pm 4.5 \dagger$ & $48.8 \pm 9.7$ \\
\hline Leg muscle mass, $\mathrm{g}$ & $1,828 \pm 336$ & $1,829 \pm 403$ & $2,216 \pm 200 *$ & $2,084 \pm 223^{*}$ \\
\hline Resting MAP, mmHg & $97 \pm 12$ & $97 \pm 13$ & $95 \pm 10$ & $99 \pm 11$ \\
\hline Resting LBF, $\mathrm{ml} / \mathrm{min}$ & $57.5 \pm 22.5 \dagger$ & $45.5 \pm 16.13$ & $81.1 \pm 30.2 * \dagger$ & $66.2 \pm 24.8^{*}$ \\
\hline Resting LVC, $\mathrm{ml} \cdot \mathrm{min}^{-1} \cdot \mathrm{mmHg}^{-1}$ & $0.59 \pm 0.25 \dagger$ & $0.46 \pm 0.17$ & $0.82 \pm 0.30 * \dagger$ & $0.68 \pm 0.30^{*}$ \\
\hline \multicolumn{5}{|c|}{ Habitual physical activity and maximum aerobic capacity } \\
\hline Inactive, hr/day & $16.2 \pm 1.8 \dagger$ & $19.7 \pm 3.1$ & $17.4 \pm 1.8$ & $18.2 \pm 1.4^{*}$ \\
\hline Light, hr/day & $6.2 \pm 1.1 \dagger$ & $3.7 \pm 2.6$ & $5.1 \pm 1.4$ & $4.7 \pm 1.2$ \\
\hline
\end{tabular}

Data are means \pm SD. BMI, body mass index; $\mathrm{HbA}_{1 \mathrm{c}}$, glycosylated hemoglobin; LBF, leg blood flow; LVC, leg vascular conductance; MAP, mean arterial pressure; $\mathrm{ND}$, nondiabetes; peak $\dot{\mathrm{V}}_{2}$, peak oxygen consumption; $\mathrm{T} 2 \mathrm{D}$, type 2 diabetes. $* P<0.05$ vs. women within same diabetes-status group (i.e., within $\mathrm{ND}$ or within T2D); $\dagger P<0.05$ vs. people with T2D within same sex. 
ratory and performed an additional two intermittent plantar-flexion bouts of $6 \mathrm{~min}$ at $70 \%$ MVC separated by a resting period of $15 \mathrm{~min}$.

\section{Calf Exercise}

Intermittent (6-s duty cycle: 2 -s contraction, 4-s relaxation) isometric plantar flexion exercise was performed with the right leg while using a custom-built calf ergometer as previously described $(6,7)$. All measurements were recorded in the supine position to remove the effects of hydrostatic pressure and to minimize cardiopulmonary baroreceptor-mediated changes in muscle sympathetic nerve activity (32). Briefly, the participant was secured to the ergometer with a harness that minimized the backward displacement of the body during each contraction. The participant's foot was attached to an immobile footplate, which was connected to its own strain gauge and against which force can be applied when the participant plantar-flexes the foot. The resultant force was amplified and sampled at $40 \mathrm{~Hz}$ before being processed by a PowerLab analog-to-digital converter (ML 795; AD Instruments) and displayed on a screen visible to the participant (Chart v6.0; AD Instruments). Participants used this visual display to control their effort and to conform to specific instructions given by the investigator.

\section{$L B F$ and $L V C$}

Resting and exercising LVC were calculated on the basis of simultaneous measurements of $\mathrm{LBF}$ and mean arterial pressure (MAP) (LVC = LBF/MAP). Blood flow was assessed using venous occlusion plethysmography (VOP). This technique has been shown to provide similar estimates of limb blood flow during calf plantarflexion exercise, very similar to the present protocol, when compared with Doppler ultrasound (10). Briefly, a mercury-silastic strain gauge (Hokanson EC-6) was placed around the widest part of the subject's right calf and connected to the plethysmograph (Hokanson EC-6). A cuff (Hokanson) placed around the upper right thigh of the subject was inflated to a constant pressure of $\sim 50 \mathrm{mmHg}$ for the duration of the exercise. A pressure of $\sim 50 \mathrm{mmHg}$ was chosen to occlude venous return without interfering with arterial blood flow. LBF during exercise was assessed by measuring the change in leg volume detected by the strain gauge over the 4-s relaxation period between contractions (6). Beat-to-beat heart rate (HR) and systolic and diastolic blood pressures were measured at rest and during exercise using either applanation tonometry of the radial artery (CBM7000; COLIN, Japan) or the volume clamp method at the level of the finger (Finometer; Finapres Medical Systems, The Netherlands). A pilot reliability study was performed $(n=10)$ to ensure that the readings attained for each of these two methods were accurate when recordings during an incremental calf plantar-flexion exercise were taken using both units simultaneously (intracorrelation coefficient $=0.82$ ). MAP was calculated from systolic and diastolic pressures (MAP: 0.33 systolic BP +0.66 diastolic $\mathrm{BP}$ ). The plethysmographic estimates of LBF, expressed relative to the resting limb volume $\left(\mathrm{ml} \cdot 100 \mathrm{ml}^{-1} \cdot \mathrm{min}^{-1}\right)$ were converted to milliliters per minute $(\mathrm{ml} / \mathrm{min})$ using an estimate of each subject's leg volume obtained from anthropometric measurements of the leg (4). LVC measures were then determined by dividing LBF responses by the corresponding MAP value $\left(\mathrm{ml} \cdot \mathrm{min}^{-1} \cdot \mathrm{mmHg}^{-1}\right)$. Additionally, LBF and LVC were also expressed relative to leg muscle mass, again, obtained from anthropometrical measurements of the leg (4).

\section{FBF and Vascular Conductance}

Forearm vascular conductance (FVC) at rest and during the 10-min postocclusion period was calculated by simultaneous measurements of FBF and MAP (FVC $=$ FBF/MAP) in the supine position. FBF was measured using the same technique of venous occlusion plethysmography described above with the mercury in-silastic strain gauge placed around the widest part of the right forearm. FBF at rest and during the reactive hyperemic response was measured by rapidly inflating (5s) and deflating $(5 \mathrm{~s})$ the arm cuff to 50 and $0 \mathrm{mmHg}$, respectively. FBF was calculated as the rate of change in plethysmographic forearm volume over the duration of the second cardiac cycle of the venous occlusion period. This was primarily because inflation of the cuff caused artifact that could have resulted in incorrect interpretation of the first cardiac cycle. Given that forearm volume was not measured, FBF responses were expressed as $\mathrm{ml} \cdot 100 \mathrm{ml} \cdot \mathrm{min}^{-1}$.

\section{Data Analysis}

Incremental test. For all study variables, values were calculated as the average over the last 30 s (i.e., final five contractions) of each workload [to allow hemodynamic variables to achieve steady state (21)]. For within-sex comparisons, individual linear regression analyses were performed between study variables (excluding responses at rest) and absolute forces and the resulting slopes of the equations were compared. To examine sex by diabetes status interactions, individual study variables (excluding resting data) were linearly fitted against force normalized to the percentage of peak force attained $\left(\% \mathrm{~F}_{\text {peak }}\right)$ to account for differences in force increments used by men and women, and the resulting slopes were compared. The vast majority of subjects showed a strong linear response, and the overall mean $R^{2}$ value for the fitted equations was $0.96 \pm 0.04$.

Constant-load tests. LVC responses for the exercise bouts at each intensity were averaged to yield a temporal profile of LVC for each subject. It was evident that in addition to the two growth phases commonly observed in the literature during low- to moderate-intensity hyperemia $(31,37)$, a fast decay phase followed the first growth phase in most responses, as recently described (33). In addition, a second slow decay (after the second growth phase) was also evident in many participants. Therefore, two empirical models represented by their corresponding functions (see below) were fitted to all the individual time series of LVC as follows:

Triphasic (two growth and one decay phases) model:

$y(\mathrm{t})=\mathrm{A}_{0}+\mathrm{A}_{1}\left\{1-e^{[-(\mathrm{t}-\mathrm{TD} 1) / \tau 1]}\right\} \mathrm{F} 1-\mathrm{A}_{2}\left\{1-e^{[-(\mathrm{t}-\mathrm{TD} 2) / \tau 2]}\right\} \mathrm{F} 2+$ $\mathrm{A}_{3}\left\{1-e^{[-(\mathrm{t}-\mathrm{TD} 3) / \tau 3]}\right\} \mathrm{F} 3$

Quadraphasic (two-growth and two-decay phases) model:

$y(\mathrm{t})=\mathrm{A}_{0}+\mathrm{A}_{1}\left\{1-e^{[-(\mathrm{t}-\mathrm{TD} 1) / \tau 1]}\right\} \mathrm{F} 1-\mathrm{A}_{2}\left\{1-e^{[-(\mathrm{t}-\mathrm{TD} 2) / \tau 2]}\right\} \mathrm{F} 2+$ $\mathrm{A}_{3}\left\{1-e^{[-(\mathrm{t}-\mathrm{TD} 3) / \tau 3]}\right\} \mathrm{F} 3-\mathrm{A}_{4}\left\{1-e^{[-(\mathrm{t}-\mathrm{TD} 4) / \tau 4]}\right\} \mathrm{F} 4$

where $\mathrm{F} 1=0$ for $\mathrm{t}<\mathrm{TD} 1$ and $\mathrm{F} 1=1$ for $\mathrm{t} \geq \mathrm{TD} 1 ; \mathrm{F} 2=0$ for $\mathrm{t}<\mathrm{TD} 2$ and $\mathrm{F} 2=1$ for $\mathrm{t} \geq \mathrm{TD} 2$; $\mathrm{F} 3=0$ for $\mathrm{t}<\mathrm{TD} 3$ and $\mathrm{F} 3=1$ for $\mathrm{t} \geq \mathrm{TD} 3$; $\mathrm{F} 4=0$ for $\mathrm{t}<\mathrm{TD} 4$ and $\mathrm{F} 4=1$ for $\mathrm{t} \geq \mathrm{TD} 4 ; y(\mathrm{t})$ is leg vascular conductance at time $t ; A_{0}$ is the baseline amplitude; $A_{1}, A_{2}, A_{3}$, and $A_{4}$ are the amplitudes; $\mathrm{TD}_{1}, \mathrm{TD}_{2}, \mathrm{TD}_{3}$, and $\mathrm{TD}_{4}$ are the time delays; and $\tau_{1}$, $\tau_{2}, \tau_{3}$, and $\tau_{4}$ are the time constants of the first (rapid growth), second (rapid decay), third (slow growth), and fourth (slow decay) phases, respectively. The parameters F1-F4 are conditional expressions that limit the fitting of a particular phase to the period at and beyond the time delay associated with that phase. The two models were fitted to LVC data using a weighted least-squares nonlinear regression procedure and the Marquardt-Levenberg algorithm (TableCurve 2D; Jandel Scientific). For all models, data that exceeded the $95 \%$ prediction intervals during an initial fit of a model were excluded. No more than four data points were removed from the original time-series of data. The steady-state amplitude, referred to as End A, for the two models was calculated as follows:

Triphasic model:

End $\mathrm{A}=\mathrm{A}_{0}+\mathrm{A}_{1}\left[1-e^{-(360-\mathrm{TD} 1) / \tau 1}\right]-\mathrm{A}_{2}\left[1-e^{-(360-\mathrm{TD} 2) / \tau 2}\right]+$ $\mathrm{A}_{3}\left[1-e^{-(360-\mathrm{TD} 3) / \tau 3}\right]$

Quadraphasic model:

End $\mathrm{A}=\mathrm{A}_{0}+\mathrm{A}_{1}\left[1-e^{-(360-\mathrm{TD} 1 / \tau 1)}\right]-\mathrm{A}_{2}\left[1-e^{-(360-\mathrm{TD} 2 / \tau 2)}\right]+$ $\mathrm{A}_{3}\left[1-e^{-(360-\mathrm{TD} 3 / \tau 3)}\right]-\mathrm{A}_{4}\left[1-e^{-(360-\mathrm{TD} 4 / \tau 4)}\right]$.

The goodness of fits of both models was compared on a pairwise basis (23). The difference $(P<0.05)$ between the fits of the two 
models was determined by calculating the $F$-test statistic for nested models as follows: $F=\left[\left(\mathrm{RSS}_{1}-\mathrm{RSS}_{2}\right) /\left(\mathrm{p}_{2}-\mathrm{p}_{1}\right)\right] / \mathrm{RSS}_{2} /\left(n-\mathrm{p}_{2}\right)$ where $\mathrm{RSS}_{1}$ and $\mathrm{RSS}_{2}$ are the residual sums of squares of the fit of the less complex $\left(\mathrm{RSS}_{1}\right)$ and more complex $\left(\mathrm{RSS}_{2}\right)$ models, $\mathrm{p}_{1}$ and $\mathrm{p}_{2}$ are the number of parameters in models, and $n$ is the number of observations in the time series. If an $F$-test value exceeded the critical $F$ value $\left(\mathrm{df}=\mathrm{p}_{2}-\mathrm{p}_{1}, n-\mathrm{p}_{2}\right.$ ), where df represents the degrees of freedom, then the more complex model was chosen as the best model of fit.

Forearm reactive hyperemia. To determine the rate of decline of postischemic FBF and FVC, these responses were fitted using a monoexponential function as follows: $y(t)=a+b\left[e^{-(c * t)}\right]$ where $b$ represents the peak amplitude of the FBF or FVC response, the rate of decline (decay constant) is characterized by c, and steady-state postischemic flow is represented by a. The area under the curve was calculated on the basis of the monoexponential fit assessed. Data were fitted using a weighted least-squares nonlinear regression procedure (TableCurve 2D; Systat). Data that exceeded the 95\% prediction intervals during an initial fit of a model were excluded, and no more than two data points were removed from the original time-series of data. Peak FBF and FVC measurements recorded at the start of the postocclusion hyperemic response were compared with the sum of the predicted baseline and amplitude of the curve-fit.

\section{Statistical Analyses}

Anthropometrical data, calf exercise performance data, cardiovascular responses during graded and constant-load calf exercise, as well as estimated parameters from the LVC kinetics and FVC and FBF kinetics responses were compared using a two-way (diabetic status vs. sex) ANOVA. Due to differences in incremental forces between sexes, within-sex differences in cardiovascular variables at absolute forces were detected using a two-way (diabetes status vs. force) ANOVA and the resulting slopes were compared using unpaired $t$-tests. Differences between groups were detected using a Bonferroni post hoc test. All statistical analyses were performed using SigmaPlot (v12; Systat Software, San Jose, CA) with the level of significance set to $P<0.05$. All values are expressed as mean $\pm \mathrm{SD}$.

\section{RESULTS}

\section{Peak Exercise Performance}

Men demonstrated significantly greater peak forces and longer times to failure compared with women during the calf plantar-flexion graded test $(P<0.001$ for all comparisons $)$ (Table 2). In addition, MVC responses were also higher in men $(P<0.001)$. No differences due to diabetes existed for these parameters (main effect $=$ diabetes status, $P=0.16$ for time to failure, $P=0.25$ for peak force, $P=0.67$ for MVC). However, individuals with T2D achieved significantly lower $(P<0.05)$ peak forces relative to their MVC compared with controls and the magnitude of this T2D-induced effect was similar among men and women (Table 2).

\section{Hemodynamic Responses During Calf Incremental Test}

Resting and peak responses. Resting LBF and LVC responses were significantly lower $(P<0.05)$ in men and women with T2D (Table 1). Peak LBF responses were also significantly lower in participants with T2D $(P<0.05)$, and these reductions were not significantly different among men and women (Table 2). Peak LVC responses tended to be lower in diabetes but they did not reach statistical significance (main effect $=$ diabetes status, $P=0.09$ ).

Submaximal responses. Between-sex comparisons showed that the slope of the fitted LBF responses as a function of relative force $\left(\% \mathrm{~F}_{\text {peak }}\right)$ were significantly lower in participants with T2D $(P<0.05)$, and the slope of the fitted LVC responses as a function of $\% \mathrm{~F}_{\text {peak }}$ tended to be lower in $\mathrm{T} 2 \mathrm{D}$ (main effect $=$ diabetes status, $P=0.08$ ). Within-sex comparisons reported that among men, for all submaximal forces, both LBF and LVC responses were significantly lower in participants with diabetes than healthy controls (Fig. 1); whereas in women LBF, data for participants with T2D were lower than for nondiabetics only at

Table 2. Exercise performance and leg hemodynamic responses during calf plantar flexion incremental exercise

\begin{tabular}{|c|c|c|c|c|}
\hline & \multicolumn{2}{|c|}{ Women } & \multicolumn{2}{|c|}{ Men } \\
\hline \multicolumn{5}{|l|}{ Performance and MAP responses } \\
\hline Time to failure, $\min$ & $6.7 \pm 1.5$ & $6.1 \pm 1$ & $8.7 \pm 1.9 *$ & $8.1 \pm 1.8^{*}$ \\
\hline $\mathrm{F}_{\text {peak }}, \mathrm{N}$ & $450 \pm 115$ & $411 \pm 71$ & $771 \pm 186^{*}$ & $727 \pm 180^{*}$ \\
\hline $\mathrm{F}_{\text {peak }}, \% \mathrm{MVC}$ & $74 \pm 21.4 \dagger$ & $63.3 \pm 11.2$ & $69.1 \pm 11.4 \dagger$ & $60.4 \pm 11$ \\
\hline Peak MAP, $\mathrm{mmHg}$ & $109 \pm 14$ & $111 \pm 11$ & $110 \pm 12$ & $110 \pm 12$ \\
\hline Peak LBF, $\mathrm{ml} / \mathrm{min}$ & $628 \pm 348 \dagger$ & $461 \pm 127$ & $731 \pm 351 \dagger^{*}$ & $622 \pm 241^{*}$ \\
\hline Absolute slope of LBF, $\mathrm{ml} \cdot \mathrm{min}^{-1} \cdot \mathrm{N}^{-1}$ & $1.21 \pm 0.52 \dagger$ & $0.84 \pm 0.29$ & $0.82 \pm 0.32$ & $0.81 \pm 0.33$ \\
\hline Relative slope of $\mathrm{LBF}, \mathrm{ml} \cdot \mathrm{min}^{-1} . \% \mathrm{~F}_{\text {peak }}{ }^{-1}$ & $5.85 \pm 3.14 \dagger$ & $3.78 \pm 1.74$ & $6.49 \pm 3.58 \dagger$ & $5.75 \pm 2.66$ \\
\hline Peak LVC, $\mathrm{ml} \cdot \mathrm{min}^{-1} \cdot \mathrm{mmHg}^{-1}$ & $5.58 \pm 3.2$ & $4.40 \pm 1.38$ & $6.57 \pm 3.54$ & $5.59 \pm 2.22$ \\
\hline Absolute slope of $\mathrm{LVC}, \mathrm{ml} \cdot \mathrm{min}^{-1} \cdot \mathrm{mmHg}^{-1} \cdot \mathrm{N}^{-1}$ & $0.012 \pm 0.008$ & $0.008 \pm 0.004$ & $0.007 \pm 0.032$ & $0.007 \pm 0.003$ \\
\hline Relative slope of LVC, $\mathrm{ml} \cdot \mathrm{min}^{-1} \cdot \mathrm{mmHg}^{-1} . \% \mathrm{~F}_{\text {peak }}{ }^{-1}$ & $0.052 \pm 0.033$ & $0.035 \pm 0.016$ & $0.057 \pm 0.037$ & $0.050 \pm 0.024$ \\
\hline \multicolumn{5}{|l|}{ Hemodynamic responses normalized for muscle mass } \\
\hline Absolute slope of LVC, $\mathrm{ml} \cdot \mathrm{min}^{-1} \cdot \mathrm{mmHg}^{-1} \cdot \mathrm{kg} \mathrm{muscle}^{-1} \cdot \mathrm{N}^{-1}$ & $0.006 \pm 0.003$ & $0.005 \pm 0.002$ & $0.003 \pm 0.013$ & $0.003 \pm 0.002$ \\
\hline Relative slope of LVC, $\mathrm{ml} \cdot \mathrm{min}^{-1} \cdot \mathrm{mmHg}^{-1} \cdot \mathrm{kg} \mathrm{muscle}^{-1} . \% \mathrm{~F}_{\text {peak }}{ }^{-1}$ & $0.029 \pm 0.019$ & $0.020 \pm 0.010$ & $0.025 \pm 0.015$ & $0.039 \pm 0.085$ \\
\hline
\end{tabular}

Data are means $\pm \mathrm{SD}$. MVC, maximal voluntary contraction; $\mathrm{F}_{\text {peak, }}$ peak force. $* P<0.05$ vs. women within same diabetes-status group (i.e., within ND or within T2D); $\dagger P<0.05$ vs. people with $\mathrm{T} 2 \mathrm{D}$ within the same sex. 

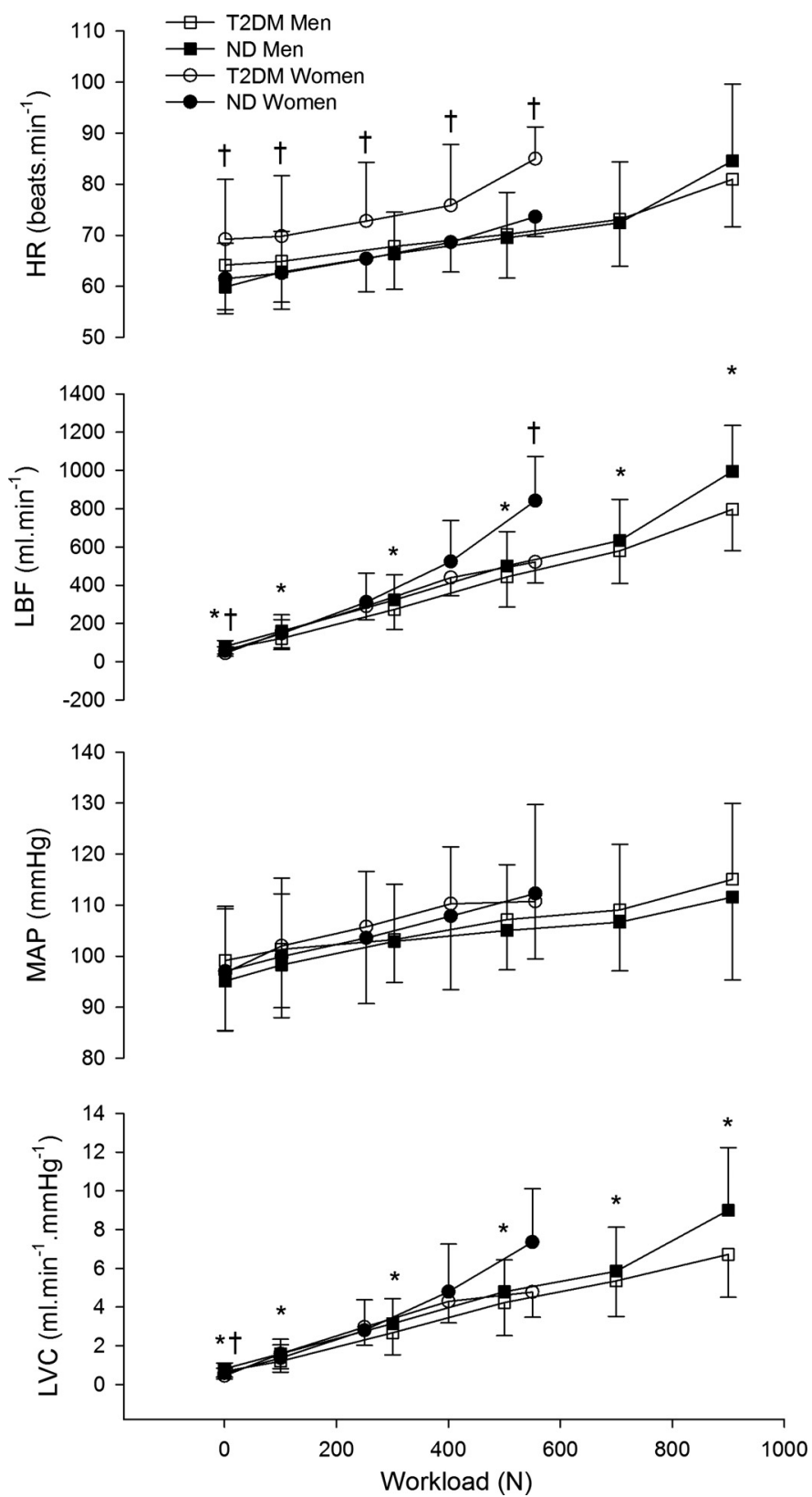

Fig. 1. Group mean \pm SD responses of heart rate (HR), leg blood flow (LBF), mean arterial pressure (MAP), and leg vascular conductance (LVC) in men and women with type 2 diabetes mellitus (T2DM) and nondiabetic (ND) controls during incremental calf exercise. ${ }^{*} P<0.05$ between men with T2DM and ND men; $\uparrow P<0.05$ between women with T2DM and ND women.

$400 \mathrm{~N}$ (diabetes status $\times$ force interaction, $P<0.05$ ), and although trends existed, no differences were observed for any submaximal $\mathrm{LVC}$ responses (main effect $=$ diabetes status, $P=0.06$ ). However, women with T2D showed a reduced hyperemic (slope of LBF vs. absolute force) response to graded calf exercise compared with nondiabetic women $(P<0.05)$, whereas within men no differences were observed (Table 2). The slope of LVC relative to absolute force during the graded test was not affected by T2D in either men or women.

Hemodynamic responses normalized for muscle mass. When data were normalized to estimated leg muscle mass, although clear trends were apparent, diabetes did not significantly affect peak LBF (main effect $=$ diabetes status, $P=0.068$ ) or peak LVC (main effect $=$ diabetes status, $P=0.17)($ Table 2$)$. The slope of $\mathrm{LBF}$ relative to $\% \mathrm{~F}_{\text {peak }}$, although not significantly different, also tended to be lower among participants with T2D (main effect $=$ diabetes status, $P=0.058$ ). Within-sex comparisons showed that among men, both LBF and LVC responses for all submaximal forces were significantly lower $(P<0.05)$ in individuals with T2D than healthy participants (Fig. 2), whereas among women, LBF responses were also lower $(P<0.05)$ for all submaximal forces in subjects with $\mathrm{T} 2 \mathrm{D}$ than healthy peers but not $\mathrm{LVC}$ responses (main effect $=$ diabetes status, $P=0.14$ ). Also among women, the hyperemic (slope of LBF vs. absolute force) response to graded calf exercise tended to be reduced in participants with T2D (main effect $=$ diabetes status, $P=0.12)($ Table 2$)$.

\section{Hemodynamic Responses During Constant-Load Exercise at $30 \%$ and $70 \% \mathrm{MVC}$}

LVC kinetics. LVC kinetic responses during plantar flexion exercise at 30\% and 70\% MVC are presented in Table 3, and
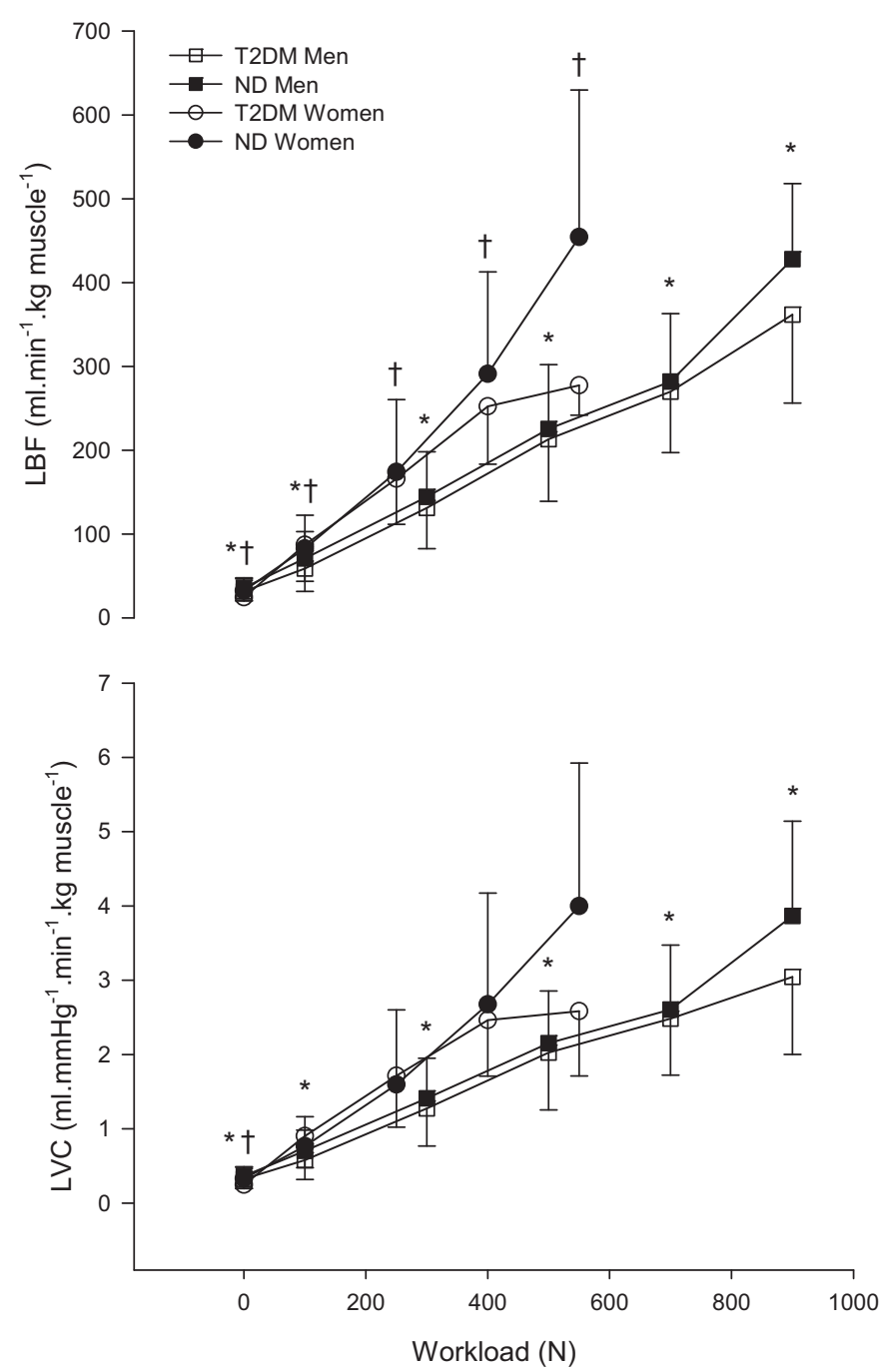

Fig. 2. Group mean \pm SD responses of LBF and LVC normalized to estimated leg muscle mass in men and women with T2DM and ND controls during incremental calf exercise. $* P<0.05$ between men with T2DM and ND men; $\dagger P<0.05$ between women with T2DM and ND women. 
Table 3. Dynamic response characteristics of leg vascular conductance during plantar flexion exercise at $30 \%$ MVC and 70\% MVC exercise intensities

\begin{tabular}{|c|c|c|c|c|}
\hline & \multicolumn{2}{|c|}{ Women } & \multicolumn{2}{|c|}{ Men } \\
\hline \multicolumn{5}{|l|}{$30 \% \mathrm{MVC}$} \\
\hline $\mathrm{A}_{1}, \mathrm{ml} \cdot \mathrm{min}^{-1} \cdot \mathrm{mmHg}^{-1}$ & $1.62 \pm 1.23$ & $2.40 \pm 0.97$ & $2.69 \pm 2.07$ & $2.23 \pm 1.24$ \\
\hline $\mathrm{TD}_{1}, \mathrm{~s}$ & $1.3 \pm 0.9$ & $0.9 \pm 0.9$ & $0.9 \pm 1.1$ & $1.1 \pm 1.8$ \\
\hline$\tau_{1}, \mathrm{~s}$ & $3.9 \pm 2.3$ & $2.8 \pm 1.9$ & $2.6 \pm 0.9$ & $3.0 \pm 2.6$ \\
\hline $\mathrm{A}_{2}$ (decay), $\mathrm{ml} \cdot \mathrm{min}^{-1} \cdot \mathrm{mmHg}^{-1}$ & $0.37 \pm 0.41$ & $0.65 \pm 0.36$ & $1.07 \pm 0.88^{*}$ & $0.88 \pm 0.67 *$ \\
\hline $\mathrm{A}_{3}, \mathrm{ml} \cdot \mathrm{min}^{-1} \cdot \mathrm{mmHg}^{-1}$ & $0.96 \pm 0.97$ & $1.09 \pm 0.57$ & $1.43 \pm 0.94$ & $1.25 \pm 0.77$ \\
\hline $\mathrm{TD}_{3}, \mathrm{~s}$ & $26.7 \pm 11.6$ & $20.3 \pm 6.9$ & $21.8 \pm 9.2$ & $21.1 \pm 8.8$ \\
\hline$\tau_{3}, \mathrm{~s}$ & $16.6 \pm 7.7$ & $18.3 \pm 15.0$ & $20.4 \pm 22.2$ & $20.3 \pm 16.6$ \\
\hline \multirow[t]{2}{*}{ End $\mathrm{A}, \mathrm{ml} \cdot \mathrm{min}^{-1} \cdot \mathrm{mmHg}^{-1}$} & $3.10 \pm 1.81$ & $3.76 \pm 1.36$ & $3.44 \pm 1.77$ & $3.03 \pm 1.13$ \\
\hline & $\mathrm{ND} n=6$ & $\mathrm{~T} 2 \mathrm{D} n=6$ & $\mathrm{ND} n=7$ & $\mathrm{~T} 2 \mathrm{D} n=14$ \\
\hline$\tau_{1}, \mathrm{~s}$ & $2.9 \pm 2.5$ & $3.6 \pm 1.8$ & $4.4 \pm 4.1$ & $3.9 \pm 2.0$ \\
\hline $\mathrm{A}_{2}$ (decay), $\mathrm{ml} \cdot \mathrm{min}^{-1} \cdot \mathrm{mmHg}^{-1}$ & $1.30 \pm 1.78$ & $0.97 \pm 0.47$ & $0.94 \pm 0.46$ & $0.67 \pm 0.58$ \\
\hline $\mathrm{TD}_{2}$ (decay), s & $9.3 \pm 1.5$ & $17.3 \pm 10.8$ & $19.0 \pm 16.3$ & $12.1 \pm 7.3$ \\
\hline$\tau_{2}$ (decay), $\mathrm{s}$ & $4.5 \pm 3.6 \dagger$ & $11.9 \pm 9.4$ & $4.2 \pm 4.3 \dagger$ & $7.8 \pm 6.0$ \\
\hline $\mathrm{A}_{3}, \mathrm{ml} \cdot \mathrm{min}^{-1} \cdot \mathrm{mmHg}^{-1}$ & $2.12 \pm 1.06$ & $2.40 \pm 0.69$ & $2.38 \pm 0.63$ & $2.27 \pm 0.75$ \\
\hline $\mathrm{TD}_{3}, \mathrm{~s}$ & $16.9 \pm 6.3$ & $22.2 \pm 4.8$ & $24.6 \pm 16.9$ & $20.7 \pm 7.3$ \\
\hline$\tau_{3}, \mathrm{~s}$ & $17.9 \pm 10.1 \dagger$ & $44.3 \pm 21.6$ & $13.6 \pm 11.1 \dagger$ & $29.2 \pm 26.6$ \\
\hline End $\mathrm{A}, \mathrm{ml} \cdot \mathrm{min}^{-1} \cdot \mathrm{mmHg}^{-1}$ & $6.47 \pm 3.55$ & $4.64 \pm 1.44$ & $7.33 \pm 1.70$ & $6.41 \pm 1.81$ \\
\hline
\end{tabular}

Data are means \pm SD. a, Baseline amplitude; $\mathrm{A}_{1}, \mathrm{~A}_{2}$ and $\mathrm{A}_{3}$, amplitudes; End $\mathrm{A}$, end-amplitude; $\mathrm{TD}_{1}, \mathrm{TD}_{2}$ and $\mathrm{TD}_{3}$, time delays; and $\tau_{1}, \tau_{2}$, and $\tau_{3}$, time constants of the first (rapid growth), second (rapid decay), and third (slow growth) phases, respectively. $* P<0.05$ vs. women within same diabetes-status group (i.e., within ND or within $\mathrm{T} 2 \mathrm{D}) ; \uparrow P<0.05$ vs. people with $\mathrm{T} 2 \mathrm{D}$ within the same sex.

representative individual plots are presented in Fig. 3. At $30 \%$ MVC intensity, of the 79 individual responses, 40 exhibited a triphasic pattern (two growth and one decay phases) and 39 a quadraphasic pattern (two growth and two decay phases). At $70 \%$ MVC intensity, of the 33 individuals, 23 exhibited a triphasic pattern and 10 exhibited a quadraphasic pattern. To enhance the physiological response and to enable more accurate estimates of the parameters defining the first three phases, a quadraphasic model was fit in subjects in whom a second decay was apparent but the second decay was not compared across groups (Table 3 ). At $70 \% \mathrm{MVC}$, the amplitude of the first growth phase $\left(\mathrm{A}_{1}\right)$ was smaller and the time constant of the second growth phase $\left(\tau_{3}\right)(P<0.01)$ was larger in individuals with T2D than nondiabetic peers, whereas the end-amplitude tended to be lower in T2D $(P=0.09)$. At the lower intensity of $30 \%$ MVC, however, the kinetic characteristics of LVC of the two growth phases were not affected by diabetes.

Forearm blood flow and vascular conductance responses during reactive hyperemia. T2D did not induce any significant effect among any of the FBF or FVC parameters following the reactive hyperemic test (results not shown). The predicted peak FBF and FVC values from the fitted model were similar among men $($ peak FBF, T2D $=22.4 \pm 5.7$, control $=20.8 \pm 5.9$ $\mathrm{ml} \cdot 100 \mathrm{ml}^{-1} \cdot \mathrm{min}^{-1}$; peak FVC, T2D $=2.16 \pm 0.65$, control $=$ $2.07 \pm 0.60 \mathrm{ml} \cdot 100 \mathrm{ml}^{-1} \cdot \mathrm{min}^{-1} \cdot \mathrm{mmHg}^{-1}$ ) and among women (peak FBF, T2D $=18.2 \pm 5.1$, control $=20.9 \pm 6.9 \mathrm{ml} \cdot 100$ $\mathrm{ml}^{-1} \cdot \mathrm{min}^{-1}$; peak FVC, T2D $=1.79 \pm 0.45$, control $=2.17 \pm$ $\left.0.64 \mathrm{ml} \cdot 100 \mathrm{ml}^{-1} \cdot \mathrm{min}^{-1} \mathrm{~mm} \cdot \mathrm{mHg}^{-1}\right)$, and these were similar to the recorded peak values among groups.

\section{DISCUSSION}

The present study provides a comprehensive assessment of hyperemic responses in muscles of the lower limb in T2D. To our knowledge this is the first study reporting peak LBF and LVC responses, and slopes of hyperemic and vasodilatory responses during an incremental test, and LVC kinetic responses during supine light and heavy exercise of the lowerlimbs in T2D. The main findings of the present study regarding the graded exercise protocol were that men and women with T2D achieved a lower peak force as a percentage of their MVC during the incremental protocol compared with their nondiabetic counterparts, and that this reduction in exercise performance was accompanied with lower maximal and near-maximal blood flow responses. The principal finding from the constant-load exercise protocols was that the T2D-induced impairment in the dynamic response of LVC is intensity dependent, which is evident at high (i.e., 70\% MVC) but not at low $(30 \% \mathrm{MVC})$ contractile intensities. The attenuated muscle performance and hemodynamic and vasodilatory responses in T2D were overall of a similar magnitude among men and women. These data confirm an initial report of impaired hyperemic responses in the legs of people with T2D (20) and demonstrate that it is specific to higher intensities of contraction. 

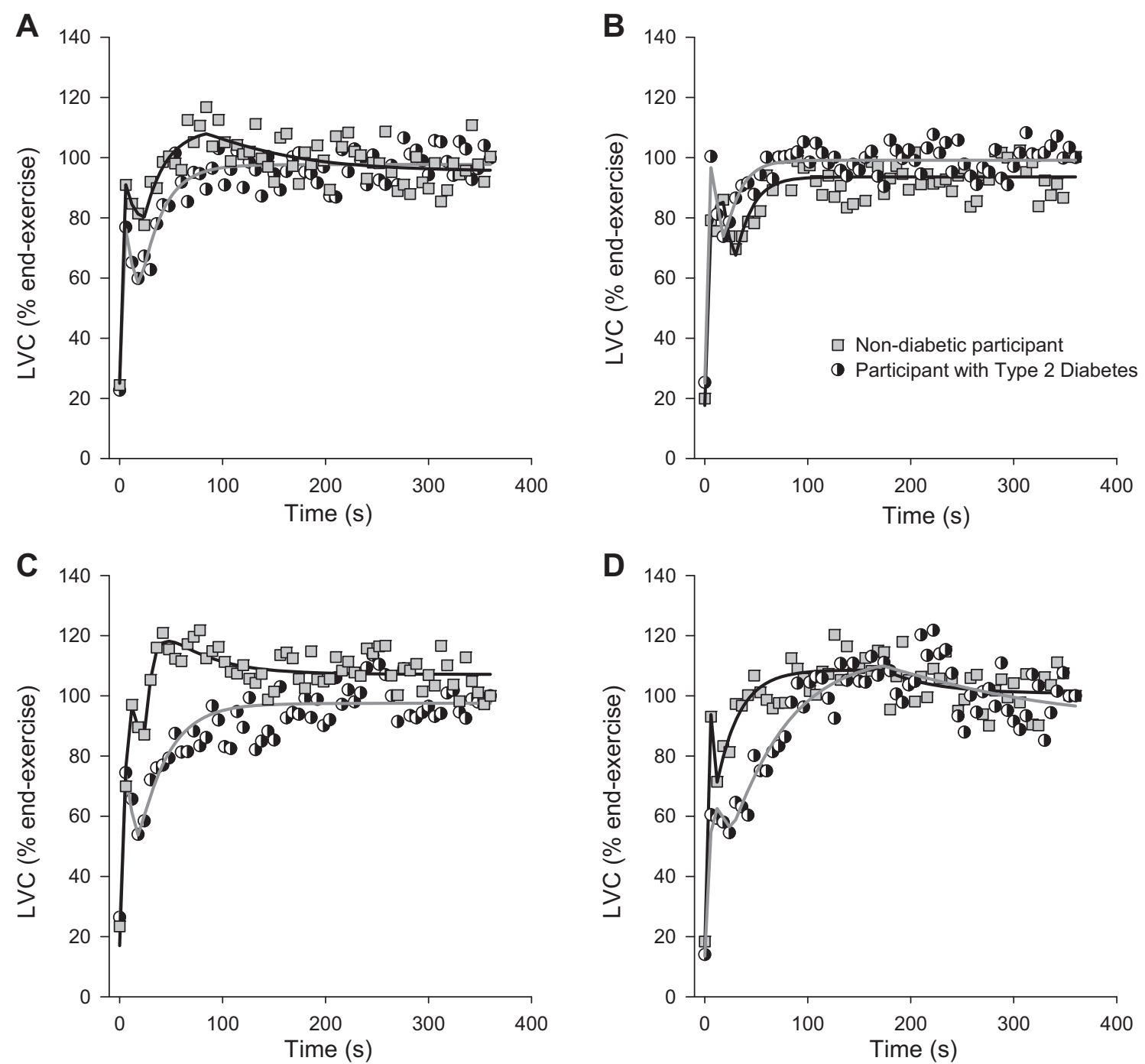

Fig. 3. LVC responses during calf exercise at intensities equivalent to 30\% MVC (top) and 70\% MVC (bottom) in representative men and women with T2DM (semiclosed circles) and ND counterparts (closed squares). A: $30 \%$ MVC among men; $B: 30 \%$ MVC among women; $C$ : $70 \%$ MVC among men; $D: 70 \%$ MVC among women. Responses predicted from the fitting of either triphasic function (two growth and one decay phases) or quadraphasic function (two growth and two decay phases) are also shown (solid lines; black lines for ND, gray lines for T2DM). LVC values are expressed relative to the end-exercise amplitude to facilitate comparisons between participants with T2DM and ND controls. Note the slower time constants of the second growth phase and the lower amplitudes of the first phase in men and women with T2D at the intensity equivalent to $70 \%$ MVC.

\section{Incremental Test}

Participants with T2D in the present study reached significantly lower peak forces relative to their MVCs compared with their healthy counterparts, suggesting a degree of impairment in muscle performance during the isolated isometric calf plantar-flexion exercise, which was of a similar magnitude among men and women. The overall magnitude of this reduction was $\sim 15 \%$, and this is consistent with the $\sim 15 \%$ lower $(P<0.05)$ peak $\dot{\mathrm{V}}_{2}$ responses observed during graded cycling exercise within these participants with T2D (Table 1). This reduction in peak $\dot{\mathrm{V}}_{2}$ is within the typical range (between 10 and 30\%) observed in the literature $(19,25,34,35,47)$. This suggests that the impairment of exercise tolerance is targeted at contracting muscles and mechanisms that limit their performance when contracting in isolation.

In the present study, to adjust for the different force increments employed in the graded tests by men and women, hemodynamic and vasodilatory responses were plotted relative to each individual's peak force, and the resulting slopes of blood flow relative to each participant's $\% \mathrm{~F}_{\text {peak }}$ were significantly reduced in T2D. It is likely that these lower slopes of LBF together with lower peak and near-peak LBF responses observed in both men and women with T2D contributed, at least in part, to the reduced peak muscle performance during the calf graded exercise test. Normalizing LBF responses to estimated leg muscle mass did not significantly influence interpretation of data during all absolute forces of the graded test (see Fig. 2), although peak and relative slopes of LBF were only marginally, not significantly, reduced $(P<0.07$ and $P<0.06$, respectively) in T2D. Thus the difference in leg muscle mass reduces the difference in peak LBF and, as a consequence, contributes to the effect of diabetes on it, but the marginal level of significance on peak LBF together with the significantly 
lower near-maximal LBF responses still suggests that other factors contribute to this effect of diabetes.

These results are in agreement with significantly reduced steady-state LBF responses during submaximal cycling (15) and leg-extension exercise (16) in humans with T2D. In contrast, Womack et al. reported similar large artery or capillary recruitment to submaximal handgrip exercise in uncomplicated diabetes (49), and Slade et al. showed similar single dorsiflexion exercise induced peak muscle blood oxygen leveldependent magnetic resonance imaging signals (39). Also, in diabetic animal models, unaltered LBF responses (5) or microvascular $\mathrm{PO}_{2}$ responses (27) were reported in GK rats and normal capillary flow responses in Zucker diabetic fatty rats (46). Considerations for these differences include the different exercise models employed, muscle groups studied, differences in blood flow measurement techniques utilized, and the fact that the GK rat represents a nonhyperinsulinemic diabetic model, whereas human participants are typically hyperinsulinemic. In addition, tissue and/or body mass content was significantly different between those with T2D and controls in some studies $(5,49)$ whereas others matched participants to body composition/mass $(15,39)$.

\section{LVC Kinetics Responses}

We have previously reported that in women with $\mathrm{T} 2 \mathrm{D}$, leg vascular conductance kinetics during heavy (70\% MVC) plantar flexion exercise (biphasic, two growth curve fitting) performed in the upright posture was significantly slowed compared with nondiabetic heavy and lean controls of similar activity levels (20). The attenuated LVC kinetic response was attributed to the slower rate of increase (i.e., larger time constant) of the second phase of the hyperemic response, whereas the first phase was unaffected by T2D. A limitation of the study by MacAnaney et al. (20) was that participants were tilted from the supine to the upright posture within $5 \mathrm{~s}$ immediately prior to the exercise bout, a maneuver that could influence the hyperemic responses by the diabetes-induced differences in the cardiopulmonary baroreceptor-mediated changes in muscle sympathetic nerve activity (32). Thus in the present study, all exercise tests were performed in the supine position, and consistent with our previous observations, we found that during heavy (70\%MVC) constant-load calf exercise the second growth phase of the LVC kinetics response was slowed in T2D. Moreover, in the present study we also observed that the amplitude of phase 1 was significantly lower in T2D, a novel finding that most likely contributed to the overall slowing of the dynamic response in diabetes. This reduced amplitude of the first growth phase in T2D probably emerged due to a more accurate parameter estimation using the triphasic and quadraphasic models, as when the same individual raw data were curve fitted using a biphasic (two-growth) model (data not shown) the differences in $\mathrm{A}_{1}$ between participants with and without T2D were not apparent.

In contrast, at the light exercise intensity (30\%MVC) both growth phases were unaffected by T2D, suggesting that at light exercise intensities, individuals with T2D may recruit other pathways to defend exercising blood flow (5). We have previously observed this intensity-dependent phenomenon on hyperemia during calf plantar-flexion exercise when muscle perfusion was manipulated in healthy individuals (6). Egaña and
Green observed that tilting the body from upright to horizontal posture resulted in a significant reduction in the amplitude of the first growth phase of the kinetic response of LVC at high contractile intensities (70\% MVC, biphasic, two-growth curve fitting), which led to a significant increase in calf muscle fatigue and reduction in endurance, but that hyperemic responses were unaffected due to body tilt at lower intensities (30\% MVC), as was the case for muscle fatigue profiles (7). In the present study, fatigue or endurance responses during constant-load exercise were not assessed, but our data imply that the impairments observed in peak calf exercise performance in T2D were mostly mediated by reductions in hemodynamic responses at higher (rather than lower) contractile intensities.

\section{Mechanisms}

The mechanisms controlling the reduced exercise-induced hyperemia in T2D are still controversial. The observation in the present study that the response to forearm reactive hyperemia were similar in people with T2D and nondiabetics is consistent with previous data (48) and suggest that the functional integrity of the vascular smooth muscle is not impaired in uncomplicated T2D. However, consideration needs to be given to the fact that vasodilation responses between arm and legs differ (24), and that insulin resistance is primarily present in leg muscles (26). Endothelial- (acetylcholine) mediated blood flow, an important mediator of the second growth phase of the hyperemic response in healthy humans (43), appears to be an important factor because it has been shown to be impaired in uncomplicated T2D when measured in the forearm $(22,48)$ and leg $(15)$; and importantly, the endothelial-mediated reduction in blood flow observed in the leg was significantly correlated with the reduction in exercise- (cycling) induced hyperemia (15).

In addition, Thaning et al. reported significantly lower LBF responses in T2D following infusions of ATP, uridine-triphosphate, and adenosine (41), suggesting that the vasodilatory response of the purinergic system, an important system linked to the regulation of exercise-induced hyperemia (9), is also impaired in T2D. The reduced secretion levels of potent vasodilators (i.e., nitric oxide and prostacyclin) and increased secretion and action of vasoconstrictors (i.e., prostanoids, angiotensin II, endothelin, and noradrenalin) reported in T2D (38) could also result in functional sympatholysis. Thaning et al. recently reported that functional sympatholysis was intact in people with T2D with normal endothelial function (42); however, given that endothelial dysfunction is a common characteristic of this disease, further studies are needed to assess whether functional sympatholysis is affected in people with T2D with endothelial dysfunction.

\section{Methodological Considerations}

Despite Longhurst et al. validating VOP as an accurate determinant of blood flow under resting conditions (18), limited studies have examined the efficacy of VOP in determining blood flow during exercise. Recently, however, Green et al. demonstrated a similar level of agreement, reporting a linear relationship between estimates of LBF when comparing LBF from a full-duty cycle (using Doppler ultrasound) vs. just during the relaxation period (VOP) (10). From this we can infer that our estimates of LBF during the incremental and 
constant-load plantar-flexion tests provide an accurate estimate of total LBF. Indeed, at the higher workloads, we can assume that LBF is occurring almost exclusively during the relaxation phase due to increasing intramuscular pressure occluding arterial flow during the contraction phase (12).

It was possible that the medications the participants with T2D were receiving in the present study may have influenced the findings, given that metformin has been shown to enhance endothelial function $(15,50)$ and that ACE-I and AIIRA have been shown to enhance insulin sensitivity in people with hypertension, and appear to have a positive effect on endothelial function, at least in nondiabetic individuals (50). However, comparison of results between metformin-treated and diettreated individuals revealed no significant differences in resting, submaximal or peak LBF and LVC values, or in the slope of the LBF and LVC responses (data not shown), as did analysis of the results excluding those individuals treated for hypertension with an ACE-I and AIIRA.

The lack of diabetes-induced sex differences in calf exercise performance and leg hemodynamic responses in the present study are limited to middle-aged participants among whom the majority of women were postmenopausal. However, given the potent beneficial effect of estrogen on the endothelium-dependent vascular function in healthy premenopausal women $(28$, 40) that is tempered by the presence of T2D to the same level as for age-matched men with T2D (40), it is possible that T2D might induce larger impairments in $\mathrm{O}_{2}$ delivery and leg exercise performance in younger premenopausal women than in age-matched men. Even if all participants in the present study were sedentary, objective measures of physical activity levels revealed that individuals with $\mathrm{T} 2 \mathrm{D}$ were more inactive than controls. Given that individuals with T2D perceive light to moderate exercise as more difficult than healthy controls (13), it is likely that harder perceived efforts during exercise might be a barrier to physical activity in T2D, which might contribute to the increased risk of cardiovascular outcomes and all-cause mortality in later life $(2,45)$. Thus the present findings suggest that diabetes is characterized by the association among exercise intolerance, impaired leg hemodynamic responses, increased perception of effort, and reduced physical activity. Further investigations are needed to substantiate these relationships and establish any underlying causality inherent in them.

In conclusion, the results of the present study suggest that $\mathrm{LBF}$, and to a lesser extent vascular conductance responses during a calf incremental exercise and the dynamic response characteristics of vascular conductance at heavy constant load intensities are impaired in T2D, and that it is possible that they could at least in part contribute to an impaired peak muscle performance in this disease. Furthermore, the magnitude of these impairments is similar between middle-aged men and women with T2D. Given that an impaired endothelium-dependent dilation may be an antecedent to atherosclerosis and peripheral vascular disease (51), future intervention strategies are needed to identify the most appropriate exercise prescriptions to speed up the leg hemodynamic responses in T2D, and reduce morbidity and improve the quality of life for sufferers of this prevalent disease. The current findings are mainly applicable to a cohort of relatively newly diagnosed individuals with T2D with good control of the disease. Further studies are required to establish the hemodynamic responses of the lower limbs in patients with long-standing but well-controlled diabetes and in patients with poorly controlled diabetes.

\section{GRANTS}

This publication has emanated from research conducted with the financial support of Science Foundation Ireland under Grant No 08/RFP/BMT1342.

\section{DISCLOSURES}

No conflicts of interest, financial or otherwise, are declared by the author(s).

\section{AUTHOR CONTRIBUTIONS}

Author contributions: C.K., E.O., D.O., S.G., and M.E. conception and design of research; C.K. and E.O. performed experiments; C.K., E.O., D.O., S.G., and M.E. analyzed data; C.K., E.O., D.O., S.G., and M.E. interpreted results of experiments; C.K., E.O., and M.E. drafted manuscript; C.K., E.O., D.O., S.G., and M.E. edited and revised manuscript; C.K., E.O., D.O., S.G., and M.E. approved final version of manuscript; M.E. prepared figures.

\section{REFERENCES}

1. Bauer TA, Reusch JE, Levi M, Regensteiner JG. Skeletal muscle deoxygenation after the onset of moderate exercise suggests slowed microvascular blood flow kinetics in type 2 diabetes. Diabetes Care 30: 2880-2885, 2007.

2. Blair SN, Wei M. Sedentary habits, health, and function in older women and men. Am J Health Promot 15: 1-8, 2000.

3. Brandenburg SL, Reusch JE, Bauer TA, Jeffers BW, Hiatt WR, Regensteiner JG. Effects of exercise training on oxygen uptake kinetic responses in women with type 2 diabetes. Diabetes Care 22: 1640-1646, 1999.

4. Clarys JP, Marfell-Jones MJ. Anatomical segmentation in humans and the prediction of segmental masses from intra-segmental anthropometry. Hum Biol 58: 771-782, 1986.

5. Copp SW, Hageman KS, Behnke BJ, Poole DC, Musch TI. Effects of type II diabetes on exercising skeletal muscle blood flow in the rat. J Appl Physiol 109: 1347-1353, 2010.

6. Egaña M, Green S. Effect of body tilt on calf muscle performance and blood flow in humans. J Appl Physiol 98: 2249-2258, 2005.

7. Egaña M, Green S. Intensity-dependent effect of body tilt angle on calf muscle fatigue in humans. Eur J Appl Physiol 99: 1-9, 2007.

8. Francesconi M, Koizar C, Wascher TC. Determinants of post-ischaemic reactive hyperaemia in patients with diabetes mellitus type II. Clin Physiol 19: $378-384,1999$.

9. Gonzalez-Alonso J, Olsen DB, Saltin B. Erythrocyte and the regulation of human skeletal muscle blood flow and oxygen delivery: role of circulating ATP. Circ Res 91: 1046-1055, 2002.

10. Green S, Thorp R, Reeder EJ, Donnelly J, Fordy G. Venous occlusion plethysmography versus Doppler ultrasound in the assessment of leg blood flow during calf exercise. Eur J Appl Physiol 111: 1889-1900, 2011.

11. Gregg EW, Gu Q, Cheng YJ, Narayan KM, Cowie CC. Mortality trends in men and women with diabetes, 1971 to 2000. Ann Intern Med 147: $149-155,2007$

12. Hoelting BD, Scheuermann BW, Barstow TJ. Effect of contraction frequency on leg blood flow during knee extension exercise in humans. $J$ Appl Physiol 91: 671-679, 2001.

13. Huebschmann AG, Reis EN, Emsermann C, Dickinson LM, Reusch JE, Bauer TA, Regensteiner JG. Women with type 2 diabetes perceive harder effort during exercise than nondiabetic women. Appl Physiol Nutr Metab 34: 851-857, 2009.

14. Kannel WB, McGee DL. Diabetes and cardiovascular disease. The Framingham study. JAMA 241: 2035-2038, 1979.

15. Kingwell BA, Formosa M, Muhlmann M, Bradley SJ, McConell GK. Type 2 diabetic individuals have impaired leg blood flow responses to exercise: role of endothelium-dependent vasodilation. Diabetes Care 26: 899-904, 2003.

16. Lalande S, Gusso S, Hofman PL, Baldi JC. Reduced leg blood flow during submaximal exercise in type 2 diabetes. Med Sci Sports Exerc 40: 612-617, 2008.

17. Lee WL, Cheung AM, Cape D, Zinman B. Impact of diabetes on coronary artery disease in women and men: a meta-analysis of prospective studies. Diabetes Care 23: 962-968, 2000. 
18. Longhurst J, Capone RJ, Mason DT, Zelis R. Comparison of blood flow measured by plethysmograph and flowmeter during steady state forearm exercise. Circulation 49: 535-540, 1974.

19. Mac Ananey O, Malone J, Warmington S, O'Shea D, Green S, Egaña M. Cardiac output is not related to the slowed $\mathrm{O} 2$ uptake kinetics in type 2 diabetes. Med Sci Sports Exerc 43: 935-942, 2011.

20. MacAnaney O, Reilly H, O'Shea D, Egaña M, Green S. Effect of type 2 diabetes on the dynamic response characteristics of leg vascular conductance during exercise. Diab Vasc Dis Res 8: 12-21, 2011.

21. Magnusson G, Kaijser L, Isberg B, Saltin B. Cardiovascular responses during one- and two-legged exercise in middle-aged men. Acta Physiol Scand 150: 353-362, 1994.

22. McVeigh GE, Brennan GM, Johnston GD, McDermott BJ, McGrath LT, Henry WR, Andrews JW, Hayes JR. Impaired endothelium-dependent and independent vasodilation in patients with type 2 (non-insulindependent) diabetes mellitus. Diabetologia 35: 771-776, 1992.

23. Motulsky HJ, Ransnas LA. Fitting curves to data using nonlinear regression: a practical and nonmathematical review. FASEB J 1: 365-374, 1987.

24. Newcomer SC, Leuenberger UA, Hogeman CS, Handly BD, Proctor DN. Different vasodilator responses of human arms and legs. $J$ Physiol 556: 1001-1011, 2004.

25. O'Connor E, Kiely C, O'Shea D, Green S, Egaña M. Similar level of impairment in exercise performance and oxygen uptake kinetics in middleaged men and women with type 2 diabetes. Am J Physiol Regul Integr Comp Physiol 303: R70-R76, 2012.

26. Olsen DB, Sacchetti M, Dela F, Ploug T, Saltin B. Glucose clearance is higher in arm than leg muscle in type 2 diabetes. J Physiol 565: 555-562, 2005.

27. Padilla DJ, McDonough P, Behnke BJ, Kano Y, Hageman KS, Musch TI, Poole DC. Effects of type II diabetes on muscle microvascular oxygen pressures. Respir Physiol Neurobiol 156: 187-195, 2007.

28. Perregaux D, Chaudhuri A, Mohanty P, Bukhari L, Wilson MF, Sung BH, Dandona P. Effect of gender differences and estrogen replacement therapy on vascular reactivity. Metabolism 48: 227-232, 1999.

29. Petrofsky JS, Lee S. The impact of rosiglitazone on cardiovascular responses and endurance during isometric exercise in patients with type 2 diabetes. Med Sci Monit 12: CR21-CR26, 2006.

30. Poole DC, Barstow TJ, McDonough P, Jones AM. Control of oxygen uptake during exercise. Med Sci Sports Exerc 40: 462-474, 2008.

31. Radegran G, Saltin B. Muscle blood flow at onset of dynamic exercise in humans. Am J Physiol Heart Circ Physiol 274: H314-H322, 1998.

32. Ray CA, Rea RF, Clary MP, Mark AL. Muscle sympathetic nerve responses to dynamic one-legged exercise: effect of body posture. Am J Physiol Heart Circ Physiol 264: H1-H7, 1993.

33. Reeder EJ, Green S. Dynamic response characteristics of hyperaemia in the human calf muscle: effect of exercise intensity and relation to electromyographic activity. Eur J Appl Physiol 112: 3997-4013, 2012.

34. Regensteiner JG, Bauer TA, Reusch JE, Brandenburg SL, Sippel JM, Vogelsong AM, Smith S, Wolfel EE, Eckel RH, Hiatt WR. Abnormal oxygen uptake kinetic responses in women with type II diabetes mellitus. J Appl Physiol 85: 310-317, 1998.
35. Regensteiner JG, Sippel J, McFarling ET, Wolfel EE, Hiatt WR. Effects of non-insulin-dependent diabetes on oxygen consumption during treadmill exercise. Med Sci Sports Exerc 27: 875-881, 1995.

36. Rowlands AV, Thomas PW, Eston RG, Topping R. Validation of the RT3 triaxial accelerometer for the assessment of physical activity. Med Sci Sports Exerc 36: 518-524, 2004.

37. Saunders NR, Pyke KE, Tschakovsky ME. Dynamic response characteristics of local muscle blood flow regulatory mechanisms in human forearm exercise. J Appl Physiol 98: 1286-1296, 2005.

38. Schalkwijk CG, Stehouwer CD. Vascular complications in diabetes mellitus: the role of endothelial dysfunction. Clin Sci (Lond) 109: 143159, 2005.

39. Slade JM, Towse TF, Gossain VV, Meyer RA. Peripheral microvascular response to muscle contraction is unaltered by early diabetes but decreases with age. J Appl Physiol 111: 1361-1371, 2011.

40. Steinberg HO, Paradisi G, Cronin J, Crowde K, Hempfling A, Hook G, Baron AD. Type II diabetes abrogates sex differences in endothelial function in premenopausal women. Circulation 101: 2040-2046, 2000.

41. Thaning P, Bune LT, Hellsten Y, Pilegaard H, Saltin B, Rosenmeier JB. Attenuated purinergic receptor function in patients with type 2 diabetes. Diabetes 59: 182-189, 2010.

42. Thaning P, Bune LT, Zaar M, Saltin B, Rosenmeier JB. Functional sympatholysis during exercise in patients with type 2 diabetes with intact response to acetylcholine. Diabetes Care 34: 1186-1191, 2011.

43. Tschakovsky ME, Saunders NR, Webb KA, O'Donnell DE. Muscle blood-flow dynamics at exercise onset: do the limbs differ? Med Sci Sports Exerc 38: 1811-1818, 2006.

44. Vaitkevicius PV, Fleg JL, Engel JH, O'Connor FC, Wright JG, Lakatta LE, Yin FC, Lakatta EG. Effects of age and aerobic capacity on arterial stiffness in healthy adults. Circulation 88: 1456-1462, 1993.

45. Wei M, Gibbons LW, Kampert JB, Nichaman MZ, Blair SN. Low cardiorespiratory fitness and physical inactivity as predictors of mortality in men with type 2 diabetes. Ann Intern Med 132: 605-611, 2000.

46. Wheatley CM, Rattigan S, Richards SM, Barrett EJ, Clark MG. Skeletal muscle contraction stimulates capillary recruitment and glucose uptake in insulin-resistant obese Zucker rats. Am J Physiol Endocrinol Metab 287: E804-E809, 2004.

47. Wilkerson DP, Poole DC, Jones AM, Fulford J, Mawson DM, Ball CI, Shore AC. Older type 2 diabetic males do not exhibit abnormal pulmonary oxygen uptake and muscle oxygen utilization dynamics during submaximal cycling exercise. Am J Physiol Regul Integr Comp Physiol 300: R685-R692, 2011.

48. Williams SB, Cusco JA, Roddy MA, Johnstone MT, Creager MA. Impaired nitric oxide-mediated vasodilation in patients with non-insulindependent diabetes mellitus. J Am Coll Cardiol 27: 567-574, 1996.

49. Womack L, Peters D, Barrett EJ, Kaul S, Price W, Lindner JR. Abnormal skeletal muscle capillary recruitment during exercise in patients with type 2 diabetes mellitus and microvascular complications. J Am Coll Cardiol 53: 2175-2183, 2009.

50. Yki-Jarvinen H. Insulin resistance and endothelial dysfunction. Best Pract Res Clin Endocrinol Metab 17: 411-430, 2003.

51. Yu HI, Sheu WH, Lai CJ, Lee WJ, Chen YT. Endothelial dysfunction in type 2 diabetes mellitus subjects with peripheral artery disease. Int $J$ Cardiol 78: 19-25, 2001. 